\title{
O MASOQUISMO ATRAVÉS DA TRANSFERÊNCIA
}

\author{
Angélique Christaki*
}

\section{Resumo}

Este trabalho propõe uma leitura psicanalítica do termo "masoquismo" partindo dos traços da obra de Léopold Sacher Masoch cuja notoriedade foi assegurada pelo sucesso desse termo cunhado pelo seu contemporâneo Richard Von Krafft Ebing. Apresentamos hipóteses relacionadas à problemática do masoquismo tal como ela pode se apresentar no contexto da transferência e da contratransferência. Identificar em uma cura o que pode se opor ao seu sucesso e perceber as causas e o que está em jogo na relação terapêutica negativa fazem parte de momentos críticos que podem estar relacionados ao masoquismo e seus efeitos. Para desenvolvermos tais reflexóes, baseamo-nos em um caso clínico de negação da gravidez.

Palavras-chave: masoquismo; transferência; corpo; gozo; negação da gravidez.

\section{Abstract}

\section{THE MASOCHISM THROUGH THE TRANSFERENCE}

This article aims to present a psychoanalytic interpretation of the term "masochism", based on the traits of the work of Léopold Sacher Masoch, wich became famous after the term was coined by Masoch's contemporary, Richard Von Krafft Ebing. It presents assumptions to masochism in the light of transference and countertransference. Identifying what may hinder healing and what is at play in and may cause a negative therapeutic reaction is one of the key moments that may be linked to masochism and its effects. The reflections herein are based on a case of pregnancy denial.

Keywords: masochism; transference; body; jouissance; pregnancy denial.

* CMPP-BAPU (Centro Médico Psico-Pedagógico e Setor de Atendimento Psicológico Universitário), Centre de Recherches Psychanalyse et Médecine (CRPM) - Universidade Denis-Diderot Paris 7 - França. E-mail: angelique.christaki@wanadoo.fr. 


\section{Segundo o capricho da soberana... ${ }^{1}$}

"E Deus o puniu, e o deixou nas mãos de uma mulher" (Deleuze, 1967, p. 119) é a frase destacada por Sacher-Masoch no início de seu romance $A$ Vênus das peles (1870/2008). Essa frase, extraída do livro de Judite, refere-se à decapitação de Holopherne pelas mãos de Judith, ato do qual Severin, o herói masoquista do romance, confessa sentir inveja. "E Deus o puniu, e o deixou nas mãos de uma mulher O que preciso fazer para que Deus me puna?" (Deleuze, 1967, p. 119), pergunta-se Severin, a futura vítima. Essa pergunta não é retórica, pois todo o romance $A$ Vênus das peles é construído em torno dessa punição como estratégia específica destinada a criar o roteiro masoquista.

Trata-se então de perceber que Severin não aspira a uma punição qualquer, mas a uma punição divina, mortal e sexuada. A partir de então, ele prepara minuciosamente o seu próprio tormento e, nessa perspectiva, nada será deixado ao acaso. Para garantir o sucesso da empreitada masoquista, Severin começa selecionando uma mulher, Wanda, que ele transformará, por meio de uma educação longa e atenciosa, em carrasco déspota e soberana caprichosa. O ponto crítico dessa longa educaçáo consiste no fato de Severin convencer sua parceira a assumir o papel do carrasco, que consente e obedece, de forma que o casal assine o contrato, sem o qual a empreitada masoquista poderia não ser bem-sucedida. Assim, "o capricho da soberana" se torna a última palavra do contrato masoquista, e é indispensável a submissão do corpo e da alma da vítima.

O que é um capricho? A etimologia do termo capricho é controversa desde a Renascença. A palavra aparece na Itália no século XIII sob a forma capo-ricio, que significa "cabeça arrepiada". Capricho é exatamente quando os cabelos se arrepiam na cabeça por um grande medo e, seguindo essa origem, tem relaçóes estreitas com a angústia - o que indica que o capricho está ligado ao corpo. Uma outra etimologia associa o termo à cabra. Daí, metonimicamente, o capricho se torna a vontade de fazer alguma coisa e, mais precisamente, se trata da vontade que dá subitamente em alguém, mas sem qualquer razão aparente, como acontece com as cabras. Diz-se que as cabras têm essa característica por natureza: quando uma salta, subitamente as outras também têm vontade de saltar e saltam juntas. O capricho remete entáo tanto a um grande medo que se apropria do corpo quanto a uma vontade súbita e inexplicável, tradicionalmente atribuída pelo homem ao temperamento feminino.

"As mulheres se alteram com frequência - louco é quem dá confiança a elas" (Hugo, 1834/2007, p. 59). Canta o rei. No entanto, Severin não é louco. É inclusive por isso que ele não confia na mulher e, como o chamam de masoquis- 
ta, procede de outra maneira: protege-se contra o temperamento caprichoso da mulher-carrasco por meio do contrato. Isso nos leva a deduzir que Severin tem uma opinião formada a respeito do universo feminino. Antes de qualquer coisa ele se deu o tempo necessário para refletir sobre o enigma da mulher, que é o enigma mais importante da natureza humana, diz ele. Em $A$ Vênus das peles, ele esclarece que o fez bem antes de Freud. Na estratégia masoquista o objetivo será o "aprendiz de carrasco" assumir o capricho da vítima como sendo seu. E é a esse capricho, ao qual o carrasco terá consentido por meio do contrato, que a vítima precisará se submeter com o seu corpo e a sua alma.

Mais especificamente, o capricho da soberana no romance de Sacher-Masoch $A$ Vênus das peles representa, por um lado, uma imagem de gosto e, por outro, uma imagem da lei, gerada pelo contrato masoquista. Entretanto, a soberania do capricho no contrato masoquista enquanto representação ao mesmo tempo do gosto e da lei não encontra a sua origem no bem ${ }^{2}$, no melhor, nem tampouco no mal, mas no corpo. Assim, o capricho constitui o equivalente a uma representação do gozo, ao "gosto do outro", o que é legitimado pelo contrato.

Mais do que fazer mal a si mesmo, o masoquista procura, primeiramente, obter uma amostra do gosto do outro. Isso significa que ele almeja roubar a pequena parte de capricho do carrasco - o seu fantasma, pode-se dizer - que, como indício do seu gozo, constitui uma figura paradigmática de uma alteridade intima. Essa alteridade íntima é, de fato, secretamente almejada pelo masoquista:

Fica aí evidente que o masoquista - para revelar [ ], para roubar no único espaço em que ele é aparentemente apreensível, [ ] o objeto (a) se entrega deliberadamente a essa identificaçáo com o objeto como rejeitado: ele é menos que nada, nem mesmo um animal, o animal que maltratamos, mas também é sujeito função de sujeito, abandonou por meio do contrato todos os seus privilégios. Essa busca, essa construção, de certa forma obstinada, por uma identificação impossível com o que se reduz ao mais extremo do lixo, [ ] que isso esteja relacionado para ele à captação do gozo (Lacan, 1966-1967/inédito).

Mais precisamente, o atormentado visa à parte íntima do Outro e, para "roubá-la”, está disposto a pagar com sua pele. A problemática trazida pela estratégia masoquista apresenta a seguinte questáo: ele está disposto a pagar o preço de que com a sua pele? 
Entretanto, essa oferta real da sua própria pele ao capricho do outro se faz de uma maneira bastante limitada, pois, embora o atormentado simule oferecer seu corpo e sua alma ao capricho cruel de Wanda, na realidade ele só se oferece de uma maneira bastante calculada. No contrato masoquista está escrito que

ao término de seis meses, esse período de servidão será considerado pelas duas partes como não tendo ocorrido e as partes não farão qualquer alusão relevante ao mesmo [ ]. Os seis meses não precisarão ser consecutivos; poderão sofrer longas interrupçóes iniciadas e terminadas de acordo com o capricho da soberana (Deleuze, 1967, p. 255).

Ele se oferece de uma maneira limitada não somente por se oferecer por meio de um contrato de duração determinada e renovável segundo o capricho da soberana (capricho que, no fundo, nada mais é do que fruto de um consentimento esclarecido entre o aprendiz de carrasco e a futura vítima), mas também pelo fato de que o "período de servidáo" - que constitui a oferta de sua pele ao Outro - fica estabelecido no contrato como isento de qualquer consequência, o que significa que fica antecipadamente estabelecido que o "período de servidáo" - a oferta de sua pele - não ocorreu. Ou seja, quais são as consequências da sua oferta, que ele náo ignora mas que teme ao ponto de se dispor a pagar um preço tão alto para que sejam consideradas como não ocorridas? Do que o masoquista se protege ao assinar o contrato?

Assim, diremos que, por meio do contrato, o masoquista se protege do possível retorno de um traço - do lugar do Outro - enquanto ressonância e consequência da oferta do seu próprio aniquilamento. Ele se protege da resposta da sua oferta no que ela pode levá-lo ao traço de uma separação subjetivante como ressonância da sua própria perda da condição de ser mortal e sexuado. Ou seja, é contra a separação e as consequências da castração que o masoquista se assegura por meio do contrato. Porém oferecer-se como vítima equivale a oferecer-se como perda, e uma oferta como tal não se restringe à estratégia masoquista. $\mathrm{Na}$ verdade, é com essa mesma dinâmica e hipótese que para todo sujeito se abre um caminho à subjetivação. O que distingue a estratégia do herói masoquista consiste no fato de que a mise en scène da sua morte faz parte de uma tentativa de proteçấo contra a opacidade do desejo do Outro, do seu carrasco e do que poderia the advir como resposta caprichosa e angustiante, como traço de alteridade.

Se a questão inicial é a mesma para todo percurso que possa se revelar subjetivante, o que diferencia a estratégia de Severin é o fato de que tal questão, quer dizer, o seu próprio aniquilamento, aparece como uma possibilidade bem 
real que ele negocia e tenta controlar por meio do contrato. Por meio do contrato, Severin garante uma verdadeira segurança contra o possível retorno da sua própria perda sob a forma de traço que poderia ser traduzido através das questóes "até onde pode ir esse carrasco?", "ele realmente tem condiçóes de ir até o fim?”. Essas questōes atingem o seu ponto máximo sob a forma "ele pode me perder?".

A diferença entre o masoquista e todo sujeito que em um determinado momento do seu percurso subjetivante possa se questionar a respeito de algo tão radical quanto isso reside no fato de que o masoquista não se limita a se apresentar tal questão, pois propóe-se vivê-la. Contudo, nessa mise en scène, a problemática consiste no risco de aniquilamento real, da própria morte, e é para proteger-se desse risco que o masoquista deve ocupar todos os lugares: ele é ao mesmo tempo o roteirista, o diretor da peça, o atormentado e o capricho do carrasco.

É dessa forma que o masoquista se garante em relação à emergência das coordenadas do desejo e da angústia, e isso através de uma estratégia com a qual busca desviar-se de toda resposta caprichosa que poderia lhe advir do lugar do outro sob a forma de traço de alteridade. Torna-se claro então que o masoquista não procura sofrer - mesmo que o sofrimento esteja em primeiro plano e inseparável do roteiro por ele construído. O que ele busca é se proteger dos efeitos da castração, se engajando em uma via que é inversa àquela que vai à sua realização.

A mise en scène do roteiro masoquista é uma demonstração pela qual a aplicação mais rigorosa do contrato confere um gozo ao masoquista, e mesmo uma ereção, aí onde esta mesma aplicação, que equivale a uma punição, deveria interditar ou ao menos limitar o acesso a esse gozo. Dessa maneira, a destituição da dor enquanto limite ao prazer nega a diferença entre corpo vivo e corpo libidinal, demonstrando que um excesso de gozo é vivido no corpo por meio dos choques e dos maus-tratos legitimados por contrato.

Assim, os maus-tratos que o masoquista recebe em seu corpo o levam a um gozo doloroso por meio do qual ele tenta negar a diferença entre prazer e gozo doloroso. Essa manobra demonstra o náo-reconhecimento da existência de um corpo libidinal marcado pela castração e apto a ser um lugar em que o prazer se legitimaria ${ }^{3}$ (Lacan, 2001). É nesse nível, o nível da demonstração da junção do corpo e do gozo, que Lacan situa a essência da função da perversão - função que vai no sentido inverso da função do sujeito, a qual visa justamente a disjunção entre o corpo e o gozo (Lacan, 1966-1967/inédito). A função da perversão é exercida com uma habilidade bastante específica pelo masoquista - "A estratégia por meio da qual ele obtém, extrai o gozo, pode ser para todos os gozos perversos imagináveis, mas esta, a estratégia masoquista, é a única nunca plenamente bem-sucedida” (Lacan, 1968/2006, p. 258). 
A demonstração dessa conjunção do corpo com o gozo é um não-reconhecimento de tudo que possa fazer diferença e aos seus efeitos. Assim, a fala sob o contrato masoquista muda de estatuto. É aí que se revela o essencial da demonstraçáo do contrato masoquista pois, com o consentimento do carrasco, a fala é destituída da sua função de alteridade. A assinatura do contrato é uma proteção contra a emergência da fala como alteridade, ou seja, contra toda emergência inesperada, incompreensível, caprichosa, traidora da alteridade mais íntima.

No que diz respeito à execução do contrato masoquista, a voz tem um papel importante. Se a essência da função da voz é uma função separadora, considerando-se que a voz separa o pensamento da fala e o leva para fora do corpo, seu local de origem, a voz fria e cruel da ordem masoquista e da execuçáo do contrato produz uma colusão entre a palavra e o pensamento. Os dois lugares, o da palavra e o do pensamento, se encontram a partir do momento em que a voz do carrasco intervém como última ordem que reconduz o pensamento do atormentado ao seu próprio corpo, ou seja, à sua própria origem. "Sua fala havia se tornado meu pensamento" diz Wanda, a mulher déspota, indicando a satisfação da mais íntima alteridade da vítima em relação ao seu carrasco, (Sacher-Masoch, 1907/1989, p. 93). Trata-se de uma voz que retira o pensamento do sujeito e o reconduz ao corpo sob forma de gozo masoquista.

Assim, distinguem-se dois níveis: no primeiro, os maus-tratos que o atormentado recebe em seu corpo o levam a um excesso de gozo. Essa estratégia se torna a demonstração da omissão da distinção entre prazer e dor, entre corpo vivo e corpo libidinal. O segundo, que depende do primeiro, busca tornar ultrapassada a essência do capricho gerado como lei pelo contrato.

\section{Período de surdez}

Se a problemática do masoquismo diz respeito a um retorno do gozo no corpo e aos seus efeitos, então como poderia ocorrer a manifestação desse fenômeno na clínica? O que está em jogo na transferência por conta desse retorno de um excesso de gozo sobre o corpo? Quais são os efeitos clínicos desse retorno? $\mathrm{E}$, se o analista escuta através dos ouvidos, orifícios a partir dos quais o corpo se implica como presença libidinal, então qual é o destino de uma fala que em seu trajeto/percurso cria a sua própria surdez?

Mas uma fala que cria sua própria surdez parece manter relaçóes das mais próximas com a ordem do entendido, ou seja, com a origem do superego, que, 
para Freud, tem suas raízes também no sentimento de culpa, e até mesmo na necessidade de punição (Freud, 1926/1986). O sentimento de culpa e a necessidade de punição se opóem, segundo Freud, a todo sucesso na análise e geram uma reação terapêutica negativa.

Propomo-nos a hipótese de que no dispositivo analítico o retorno de um excesso de gozo, ou seja, a chegada de algo ensurdecedor, pode interromper a fala analisante, ou seja, torná-la surda aos seus próprios efeitos sobre o sujeito. Mas como perceber tal fala na transferência, como analisar ou transmitir os efeitos de uma fala que não ouvimos, que não experimentamos, que não tem ressonância?

Essa surdez imprevisível pode ser o caso de quando um certo masoquismo ocorre na transferência. Isso me faz pensar em uma paciente que, devido a uma insensibilidade exemplar em relação ao seu próprio corpo, induziu uma surdez e uma cegueira em princípio no seu próprio corpo medical e em seguida em outros locais de escuta que náo os medicais. $\mathrm{O}$ que ela induziu a si foi uma anestesia e uma surdez crônicas que poderiam ter chegado a causar a sua própria morte e a morte do seu bebê.

Trata-se especificamente de uma paciente que chamarei de M. L. que, após muitas passagens e hospitalizaçóes em hospital geral, completou oito meses de gravidez sem que um médico tenha demonstrado ter tomado conhecimento da negação de gravidez da qual ela era vítima. A gravidez não foi percebida pelos médicos que a atendiam regularmente por conta de problemas crônicos de saúde, tampouco por seu marido, pelo restante da família, nem pela psicóloga que acompanhava o seu filho durante esse período.

Sem me referir diretamente a essa paciente que atendi durante alguns anos e que não considero como masoquista, gostaria simplesmente de insistir na negativação da vida que acontece na negação da gravidez e que me parece um protótipo do efeito do retorno do gozo sobre o corpo, ou seja, de um certo masoquismo que acontece. Essa negativação pura, que produziu efeitos anestesiantes sobre o próprio corpo e sobre o corpo médico, constitui uma modalidade bastante esclarecedora da relação da paciente com o Outro e a falta, relação que ela também estabeleceu na transferência comigo. Parece-me então necessário - ainda que sem poder precisar a natureza desses momentos na transferência - dizer ao menos o que me parece não estar em relação.

Reforço que tais efeitos na transferência, os quais podemos qualificar de anestesiantes, não são associados nem a momentos penosos, pois os momentos penosos não fazem parte de nenhuma anestesia, nem a momentos de inquietante estranheza. Eu diria que não se trata tampouco de momentos de relação com 
qualquer tipo de tédio, pois o tédio pode ser remetido a alguma positividade. Náo se trata tampouco de momentos em que o analista não pensa, momentos que podem testemunhar uma liberação da angústia do saber, liberação determinante (se seguimos Lacan) para o ato analítico, ou seja, para a possibilidade posterior e seus efeitos.

Mais particularmente, proponho como hipótese de trabalho a ideia de que, no nível da clínica, um certo masoquismo ocorre quando a escuta do analista se encontra absorvida pelo que não ecoa, pelo que não deixa traço na transferência. Entretanto, parece-me que um "período de servidão" que poderia surgir na cura, para retomar os termos do contrato masoquista, e que submeteria a escuta do analista à força negativante de uma fala durante um tempo não é da ordem de algo que poderíamos evitar. Acredito que se trata mais de uma necessidade, um tipo d'anankè inerente à temporalidade da emergência da fala e entáo da transferência na cura. E, nesse sentido, parece-me que esse "período de servidáo" da escuta do analista aos efeitos anestesiantes e ensurdecedores de uma fala constitui a questão do destino da cura e suas consequências.

A questão que se apresenta é como lidar com um capricho que tem por especificidade o fato de não ser perceptível. Como perceber uma pura negatividade na transferência e na contratransferência de forma que ela possa ser transformada em matéria analisável no processo analítico? Mais especificamente, proponho como hipótese clínica que uma fala que se encontra absorvida em nichos anestesiantes da transferência poderia produzir efeitos masoquistas, ou seja, efeitos que dificultam o desenvolvimento da análise. É no limite dessa dinâmica que se encontram tanto os efeitos criativos da análise, que testemunham uma separaçáo do funcionamento masoquista, quanto os efeitos que sustentam a reação negativa na transferência e a expressão da pulsão de morte quando o masoquismo inerente à cura impede sua evolução.

Assim, uma boa parte da criatividade da transferência reside na possibilidade que o analista tem de distanciar sua escuta desse "período de servidáo" na transferência. Esse afastamento enquanto um afastamento da transferência na transferência é um momento crítico. Ele reproduz o destino do trauma, que poderia se presentificar também como a possibilidade de inscrever na transferência um traço que poderá, por sua vez, estar em ressonância com um traço de um desaparecimento do que, de fato, nunca ocorreu. É nesse sentido que o afastamento da transferência feito pelo analista na transferência pode representar uma possibilidade em um segundo tempo.

Mais especificamente, as modalidades desse momento de separação criam um afeto que autentifica uma perda na transferência que pode se enraizar no cor- 
po e dele extrair um gozo. É nesse nível que o ato analítico segue o sentido inverso ao da função essencialmente masoquista, que visa levar o gozo ao corpo. Afastar-se de uma fala ensurdecedora pertence à criatividade em cada transferência, mas náo poder se afastar também é uma possibilidade. E essa possibilidade depende bastante do masoquismo que ocorre em uma cura e se desenvolve no campo da pulsão de morte, da repetição e da reação terapêutica negativa.

Conduzir a fala aos seus próprios recursos criadores concerne ao ato analítico, um ato que "se institui em abertura de gozo como masoquista, que deste reproduz o arranjo, o psicanalista corrige a hybris com uma segurança: a de que nenhum de seus pares mergulhe nessa abertura e, portanto, a de que ele próprio saberá manter-se na borda" (Lacan, 2001, p. 348).

Ou seja, o analista, por meio do seu ato, reproduz o arranjo de um gozo. $\mathrm{O}$ ato do analista se institui por meio da abertura mesma desse gozo como masoquista, porque o analista corrige a sua hybris, ou seja, extrai o excesso desse gozo, talvez mesmo dessa segurança - sob a condição de que ele não se perca na abertura desse gozo masoquista e se mantenha na borda com seus pares. Eu diria então que, nessa ginástica que permite se manter na borda de um gozo que será inevitavelmente questão na cura, o analista não está protegido. Nesse contexto, ao contrário do masoquista, o analista não possui seguro ou contrato. E, contrariamente ao contrato masoquista, o contrato analítico é destinado a intervir como condição para a emergência de alguma coisa inesperada. Por sua vez, o contrato masoquista é o lugar da impossibilidade e da proibição de qualquer surpresa que poderia surgir como capricho do inconsciente. Assim, "somente a experiência permite se manter na borda dessa abertura sob a condição de que se esteja muito certo de onde a experiência se fecha para cada um" (Lacan, 2001, p. 348).

\section{Conclusáo}

Propusemos uma reflexão que situa o masoquismo para além de um quadro clínico estritamente reservado ao campo da perversáo. O movimento masoquista - que tende a retornar o gozo ao corpo, visando a indiferenciação entre o gozo e o prazer, entre corpo vivo e corpo libidinal - vai de encontro aos processos de separação e desalienação. Assim, os efeitos do funcionamento masoquista podem se encontrar em cada estrutura e constituem momentos críticos que tornam difíceis os processos de subjetivação.

Mais precisamente, os efeitos do funcionamento masoquista, tais como aparecem na cura, atravessam sua evolução e podem estar na origem de reaçôes 
terapêuticas negativas. Entretanto, desses momentos inevitáveis que mobilizam as resistências mais poderosas na transferência e na contratransferência depende a transmissáo do que parece estar na borda do analisável, ou seja, do que pode ser falado e ser escutado.

Porém tornar analisáveis os impasses da transferência constitui uma via que vai de encontro ao funcionamento masoquista. Nesse sentido, transformar os nichos anestesiantes de uma análise em material analisável e tornar evidentes os significantes dos enclaves anestesiantes da escuta analítica constitui um caminho de desalienação e permite a liberação de um gozo masoquista.

Entretanto, o funcionamento masoquista e seus efeitos ensurdecedores intervêm tanto no nível da intimidade na cura analítica quanto no nível institucional encarregado da transmissão da psicanálise. Mais especificamente, os efeitos do funcionamento masoquista são percebidos onde o extraordinário de um gozo masoquista luta para se transformar em possibilidade de escutar, analisar e transmitir, onde a fala se torna contratual e perde o seu estatuto de alteridade.

Nessas circunstâncias, as dinâmicas masoquistas, que mantêm relações bastante próximas com a pulsão de morte, se encontram na base do que, incrustado em um gozo, permanece fora da transmissão, tais como os significantes extraordinários do trauma. Tornar audíveis esses significantes e extrair o excesso de gozo a partir da demanda desenvolvida na transferência permite devolver à fala a sua função separadora e abrir caminho à subjetivação.

Estar alertado quanto ao funcionamento masoquista, tentar tornar evidente a escuta da negativação ensurdecedora constituem as vias que vão de encontro ao que, do funcionamento masoquista, garante a emergência de uma fala ensurdecedora. $\mathrm{Na}$ verdade, é a partir de um questionamento como esse que a problemática masoquista como um tipo de anankè poderia ser a fonte de todas as criatividades bem temperadas.

\section{Referências}

Deleuze, G. (1967). Présentation de Sacher-Masoch, avec le texte intégral La Vénus à la fourrure. Paris: Éditions de Minuit.

Freud, S. (1926). Inhibition, symptôme et angoisse. S. Freud, Oeuvres complètes, v. 17. Paris: PUF, 1986.

Freud, S. (1929). Malaise dans la civilisation. Paris: PUF, 1971.

Hugo, V. (1832). Le roi samuse. Paris: Éditions Benjamin Girault, 2007

Lacan, J. (1966-1967). La logique du fantasme, inédito. 
Lacan, J. (2001). Autres écrits. Paris: Éditions Seuil.

Lacan, J. (1968). Séminaire, Livre XVI, D’un Autre à l'autre. Paris: Editions Seuil, 2006.

Sacher Masoch, L. (1870). A Vênus das peles. São Paulo: Hedra, 2008.

Sacher Masoch, W. (1907). Confession de ma vie. Paris: Editions Gallimard, 1989.

\section{Notas}

${ }^{1}$ Os textos estrangeiros citados neste artigo foram consultados no francês e livremente vertidos para o português pela tradutora.

${ }^{2}$ A Lei se funde sobre ela mesma e ela se funde caprichosamente. Trata-se da inversão operada pelo pensamento de Kant, considerando que a novidade do seu método consiste no fato de que a lei não depende do Bem como no caso do pensamento de Platão. Kant inverte a dialética platônica que fundava a lei a partir do Bem como princípio superior. Isso quer dizer que a lei não pode mais se fundar sobre o princípio superior do qual ela extrairia seu direito. Assim, Kant faz da lei um fundamento último, o que quer dizer que a lei se torna caprichosa. "De fato, se a lei não é mais fundada sobre um Bem prévio e superior, se ela vale por sua própria forma que deixa seu conteúdo indeterminado, torna-se impossível dizer que o justo obedece à lei para o melhor. Ou então: aquele que obedece à lei nem por isso é ou se sente mais justo. Pelo contrário: sente-se culpado, é previamente culpado e se sente ainda mais culpado na medida em que ele obedece mais estritamente à lei [...]. Coube a Freud realçar esse fantástico paradoxo da consciência moral: por menos que nos sintamos mais justos nos submetendo à lei, ela [...] mais severamente se comporta e maior desconfiança manifesta quanto mais virtuoso for o sujeito". Freud, Malaise dans la civilisation (1929/1971, p. 60), citado por Gilles Deleuze em Présentation de Sacher-Masoch, Le froid et le cruel (1967, p. 74).

${ }^{3}$ Lacan, em Autres écrits (2001, p. 357), estipula que a estratégia masoquista demonstra "o que acontece com o corpo para todos - que ele é, justamente, esse deserto”.

Recebido em 10 de dezembro de 2011 Aceito para publicação em 27 de março de 2012 